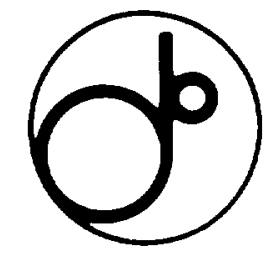

KEK Preprint 96-26

May 1996

A

\title{
Cooling Performance of a Pressurized HeII Cryogenics System for the Superconducting Magnet Test Facility at KEK
}

N. KIMURA, Y. AJIMA, Y. DOI, T. HARUYAMA, N. HIGASH, M. IIDA, S. KATO,

M. KAWAI, H. KAWAMATA, S.W. KIM, Y. KONDOU, Y. MAKIDA, K. MIMORI,

S. MIZUMAKI, T. NAKAMOTO, T. OGITSU, H. OHHATA, N. OHUCHI, S. SUGAWARA, T. SHINTOMI, K. TANAKA, A. TERASHIMA, K.TSUCHIYA, H. YAMAOKA and A. YAMAMOTO

Submitted to the 16th International Cryogenic Engineering Conferencel International Cryogenic Materials Conference,

Kitakyushu, Japan, May 20 - 24, 1996.

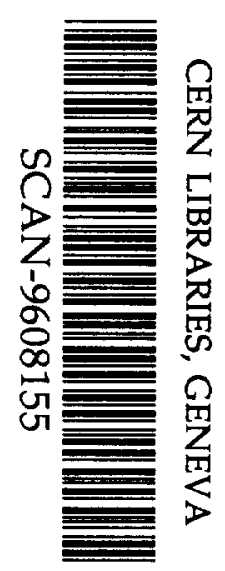


National Laboratory for High Energy Physics, 1996

KEK Reports are available from:

Technical Information \& Library

National Laboratory for High Energy Physics

1-1 Oho, Tsukuba-shi

Ibaraki-ken, 305

JAPAN

Phone: $0298-64-5136$

Telex: 3652-534 (Domestic)

(0)3652-534 (International)

Fax: $\quad$ 0298-64-4604

Cable: $\quad$ KEK OHO

E-mail: Library@kekvax.kek.jp (Internet Address)

Internet: http://www.kek.jp 
Nobuhiro Kimura, Yasuo Ajima, Yoshikuni Doi, Tomiyoshi Haruyama, Norio Higashi, Masahide Iida, Shuichi Kato *, Masanori Kawai, Hiroshi Kawamata, Seog-whan Kim, Yoshinari Kondou, Yasuhiro Makida, Katsuhiro Mimori, Shoichi Mizumaki **,

Tatsushi Nakamoto, Toru Ogitsu, Hirokatsu Ohhata, Norihito Ohuchi, Shigekatsu Sugawara, Takakazu Shintomi, Ken-ichi Tanaka, Akio Terashima, Kiyosumi Tsuchiya, Hiroshi Yamaoka, and Akira Yamamoto

National Laboratory for High Energy Physics (KEK), 1-1 Oho, Tsukuba, Ibaraki 305, Japan

* Kyushu University, Fukuoka, 812, Japan

** The Graduate University for Advanced Studies, 1-1 Oho, Tsukuba, Ibaraki 305, Japan

This paper describes a new cryogenic test facility developed at KEK for research and development on high field superconducting magnets. It consists of a vertical double-bath cryostat for $1 \mathrm{~m}$ model magnets in superfluid helium at atmospheric pressure associated with a vacuum pumping system and a refrigerator/liquefier. The system has been successfully operated since 1995 with a refrigeration power of $8 \mathrm{~W}$ at $1.9 \mathrm{~K}$, and two superconducting magnets have been tested.

\section{INTRODUCTION}

A cooperative effort to develop high field superconducting magnets has been carried out between CERN \& KEK, as part of the joint research program towards the Large Hadron Collider to be built at CERN. A series of high field superconducting model magnets are being developed at KEK $[1,2,3]$.

To test those magnets, a new $1.8 \mathrm{~K}$ test facility has been developed at $\mathrm{KEK}$, and a cooling performance test has been carried out by using a dipole model magnet. This paper describes the results of the performance test, of the $1.8 \mathrm{~K}$ test facility.

\section{TEST FACILITY}

A flow diagram of the test facilities cryogenics system is shown in Figure 1. The cryogenics system consists of a refrigerator/liquefier, a valve connection box, a vertical double bath cryostat with a heat exchanger and a pumping system $(1.8 \mathrm{~K}$ refrigerator) which provides saturated superfluid helium inside the heat exchanger. The refrigerator/liquefier was built by Teisan/L'Air Liquide and was previously used for the superconducting solenoid in the AMY detector system at TRISTAN[4]. Its cooling power is $300 \mathrm{~W}$ at $4.4 \mathrm{~K}$ or its liquid helium production capacity is $100 \mathrm{~L} / \mathrm{h}$. During cool down of the magnet, it works as a refrigerator. In steady state, it works as a liquefier. Major parameters of the cryogenics system are listed in Table 1.

Table 1. Parameters of the cryogenics system

Cold box

Liquid He Dewar

Liquid Nitrogen Tank

$1.8 \mathrm{~K}$ Heat Exchanger area

Vacuum Pumping

He gas recovery
$100 \mathrm{~L} / \mathrm{h}(300 \mathrm{~W}$ at $4.4 \mathrm{~K})$ with LN2

2500 Liters +2000 Liters

9700 Liters

$0.75 \mathrm{~m}^{2}$

$900 \mathrm{~m}^{3} / \mathrm{h}$ at $13 \mathrm{kPa}$ (Roots pump) $+360 \mathrm{~m}^{3} / \mathrm{h}$ (Rotary pump)

$100 \mathrm{~m}^{3} / \mathrm{h}$ (Recovery compressor) $+20 \mathrm{~m}^{3}$ (Gas bag) 


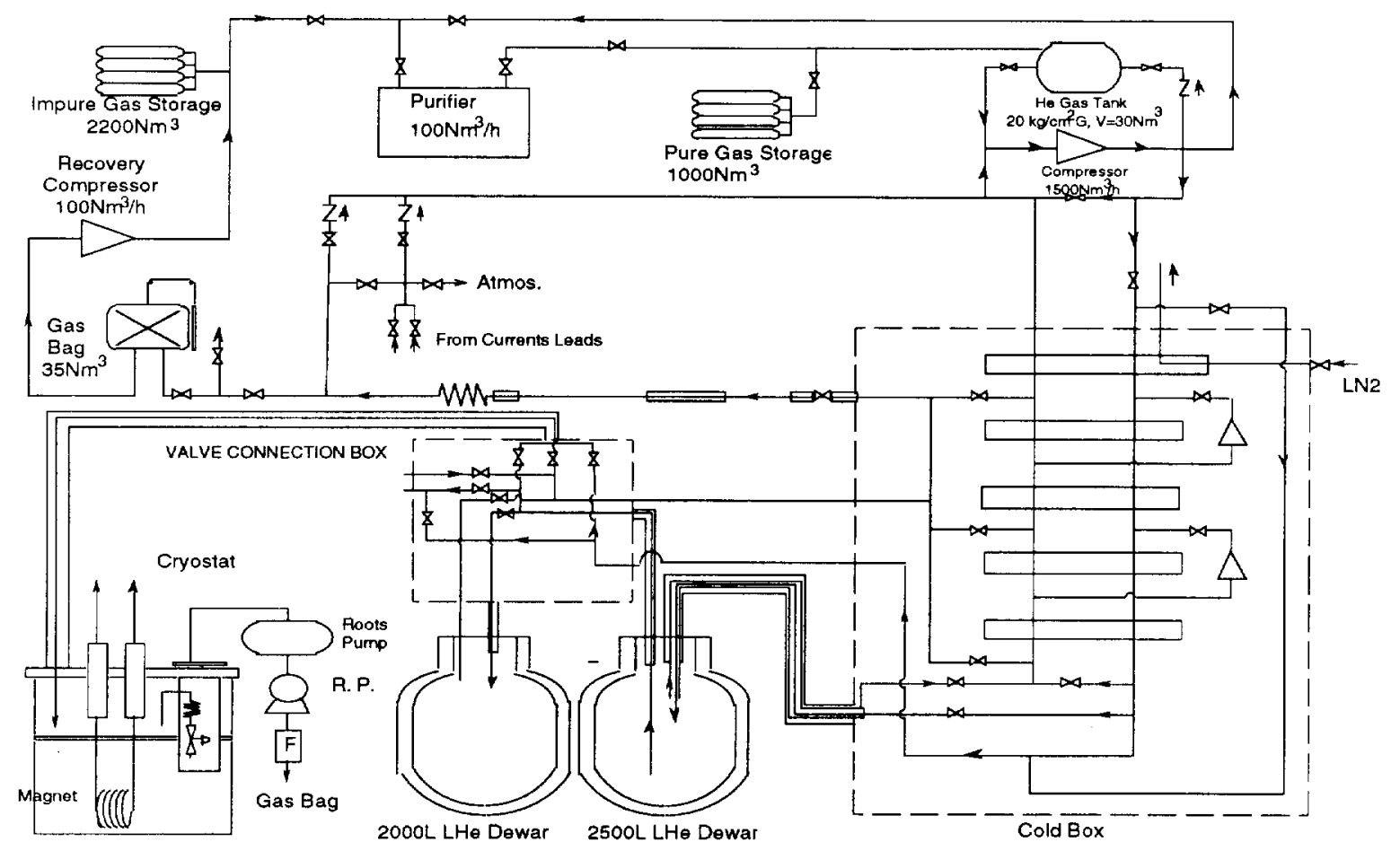

Figure 1 Flow diagram of the cryogenics system for testing superconducting magnets.

The cryogenics system is controlled by a distributed process control system with modified automatic control programs converted from the AMY superconducting solenoid control system[4]. The cryostat for the model magnet is $800 \mathrm{~mm}$ in diameter, $2670 \mathrm{~mm}$ in depth, with a GFRP insulating plate between $1.8 \mathrm{~K}$ and $4.2 \mathrm{~K}$ helium baths as shown in Figures 2 (a) and (b). Liquid helium capacity in each bath is $450 \mathrm{~L}$ for $1.8 \mathrm{~K}$ bath and $130 \mathrm{~L}$ for $4.2 \mathrm{~K}$ bath, respectively. A heat exchanger with a J-T valve is equipped in the $1.8 \mathrm{~K}$ bath. The pumping system consists of a $900 \mathrm{~m}^{3} / \mathrm{h}$ roots pump linked with a 390 $\mathrm{m}^{3} / \mathrm{h}$ rotary pump. The superconducting model magnet with a cold mass weight of about 2.5 tons which was suspended from the insulating plate was immersed in the $1.8 \mathrm{~K}$ pressurized super fluid helium bath. The cryostat is equipped with two thermal screens cooled with cold helium vapor gas and a two stages G-M type cryocooler.

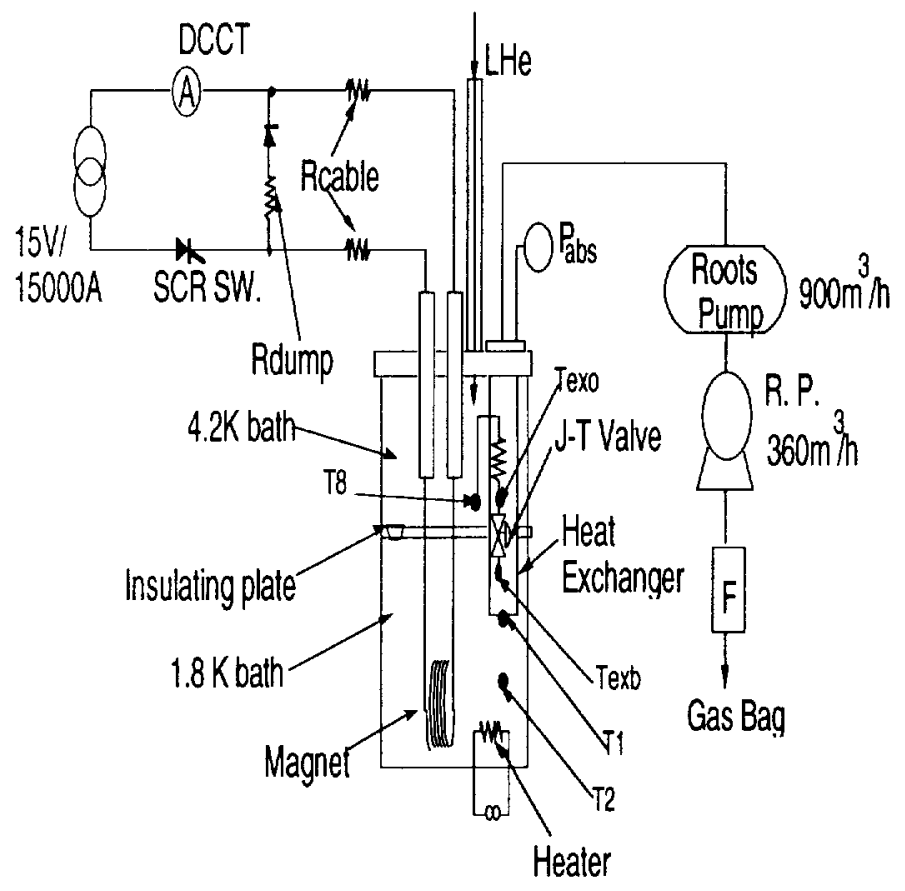

Figure 2. (a) A schematic diagram of the cryostat

(b) a photograph of a set up of the magnet with the heat exchanger and GFRP insulating plate.

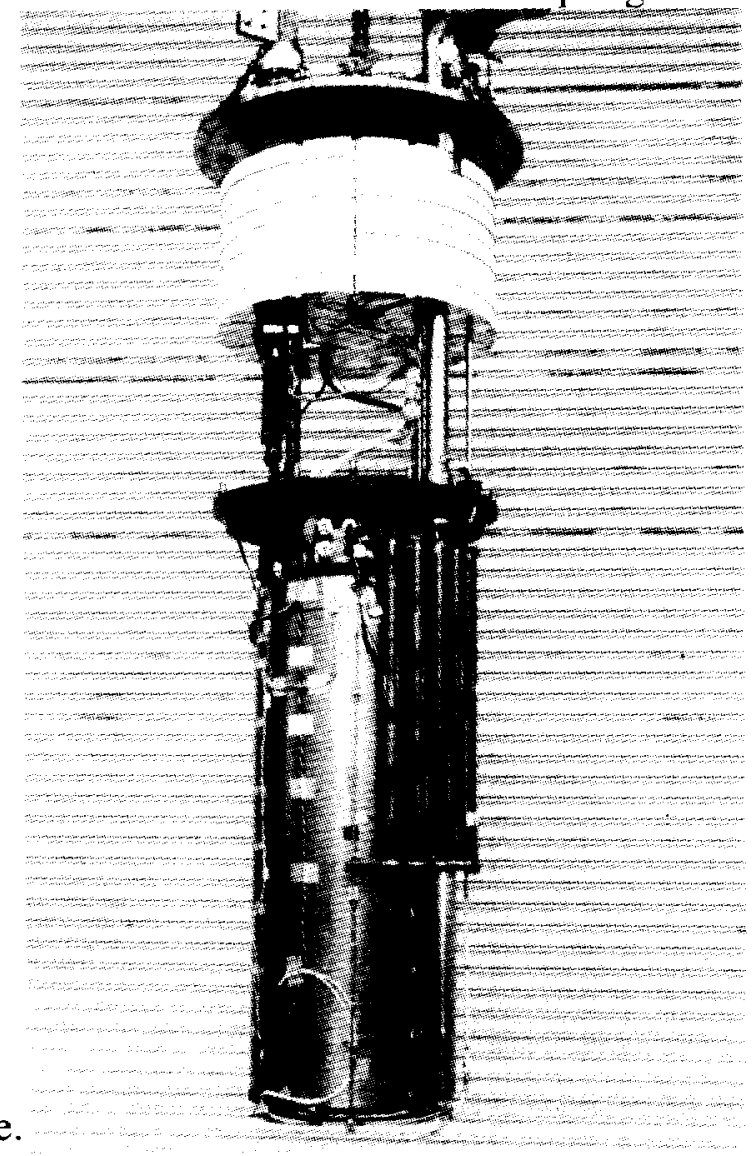


The power supply for the magnet test has a capacity of $15 \mathrm{kA}$ with $15 \mathrm{~V}$ and a stability of $10^{-4}$. The monitoring system provides 96 channels with sampling frequencies of 0.1 to $1 \mathrm{~Hz}$ for monitoring cool down or warm up of the magnet.

\section{PERFORMANCE TEST AND RESULTS}

The cryogenics performance of the $1.8 \mathrm{~K}$ test facility has been carried out during a test period of a dipole magnet. For precise measurement of the cooling characteristics and the refrigeration power five carbon glass resistance thermometers were installed in the cryostat as indicated in Fig. 2. The five thermometers are positioned in the cryostat at the: inlet of the $1.8 \mathrm{~K}$ refrigerator $\left(\mathrm{T}_{8}\right)$, after the precooler $\left(\mathrm{T}_{\text {exo }}\right)$, at the outlet of the J-T valve $\left(\mathrm{T}_{\mathrm{exb}}\right)$, at the surface of the heat exchanger $\left(\mathrm{T}_{1}\right)$, and in the 1.8 $\mathrm{K}$ pressurized helium bath $\left(\mathrm{T}_{2}\right)$.

The cooling process follows two cooling schemes. In the temperature range $300 \mathrm{~K}-80 \mathrm{~K}$, the magnet was cooled down using cold helium gas at about $50 \mathrm{~K}$ lower than the magnet temperature to eliminate excessive thermal stresses. Helium mass flow rate and gas temperature were automatically controlled to keep the temperature difference within $30 \mathrm{~K}$ between the He gas-inlet and the magnet temperature. Below $80 \mathrm{~K}$ where the thermal shrinkage becomes negligible, it was cooled quickly to liquid helium temperature by using the liquid helium which was fed to the cryostat from a $2500 \mathrm{~L}$ dewar via the valve connection box. After magnet training at $4.2 \mathrm{~K}$, the magnet was cooled down to $1.8 \mathrm{~K}$ by flowing helium through the $1.8 \mathrm{~K}$ heat exchanger at low pressure.

Figure 3 shows the typical cool-down curve of the magnet from $300 \mathrm{~K}$ to $4.2 \mathrm{~K}$, and from $4.2 \mathrm{~K}$ to 1.8 $\mathrm{K}$. By using this cryogenics system, the cool-down time of the model magnet from $300 \mathrm{~K}$ to $4.2 \mathrm{~K}$ took $2 \sim 3$ days, and the cool-down time from $4.2 \mathrm{~K}$ to $1.8 \mathrm{~K}$ took 6 hours.

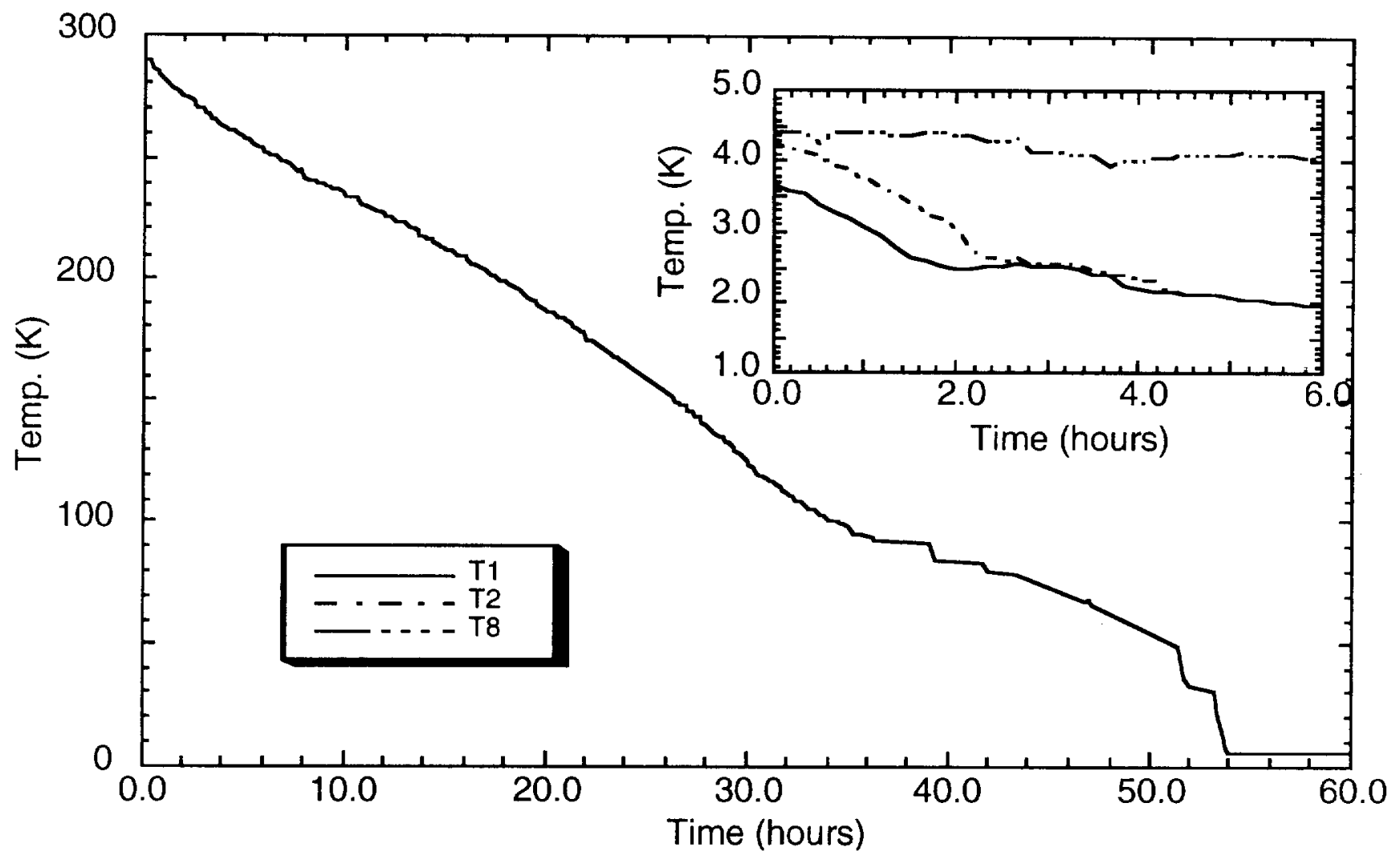

Figure 3 Cool-down characteristics of the model magnet from $300 \mathrm{~K}$ to $4.2 \mathrm{~K}$, and from $4.2 \mathrm{~K}$ to $1.8 \mathrm{~K}$.

The refrigeration characteristics of the $1.8 \mathrm{~K}$ refrigerator were measured as a function of temperature by changing the electrical heater power. Figure 4 shows the refrigeration characteristics of the $1.8 \mathrm{~K}$ refrigerator as a function of temperature. A solid line in Fig. 4 represents the theoretical prediction for the ideal refrigeration power given by

$$
\mathrm{Q}=\lambda \bullet \rho \bullet \dot{\mathrm{m}}
$$


where $\lambda$ is the latent heat of the liquid helium, $\rho$ is the density of the helium gas, and $\dot{m}$ is the mass flow rate of the pumping system. In this figure, the lowest obtained temperature of the cryostat was $1.73 \mathrm{~K}$ with no heater load, and the refrigeration power of $8 \mathrm{~W}$ was obtained at $1.9 \mathrm{~K}$.

With this capacity, five training cycle of the magnet have been performed within 10 hours, with a temperature profile as shown in Fig. 5.

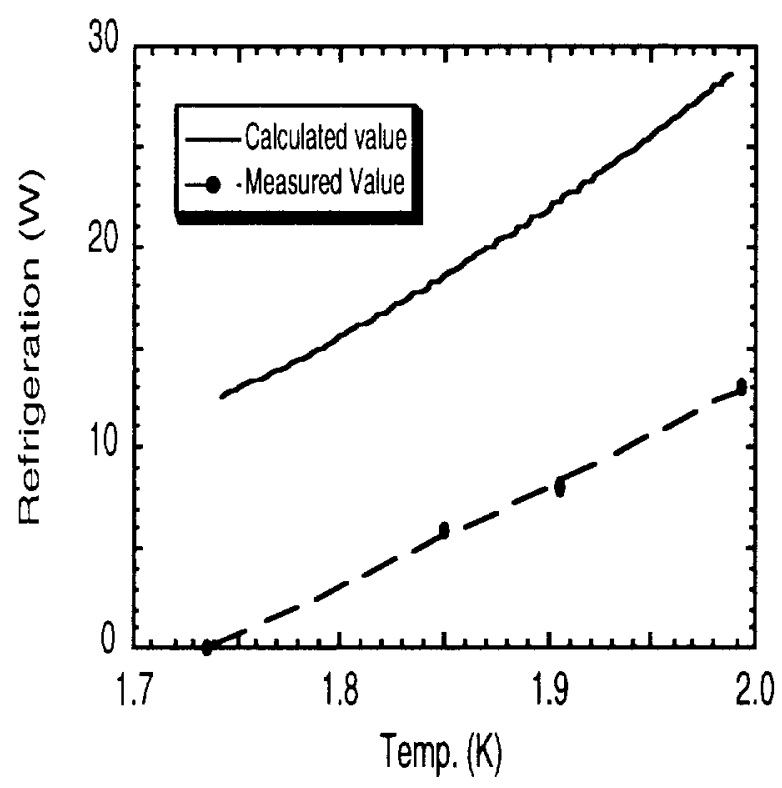

Figure 4 Measured refrigeration power at the superfluid helium region.

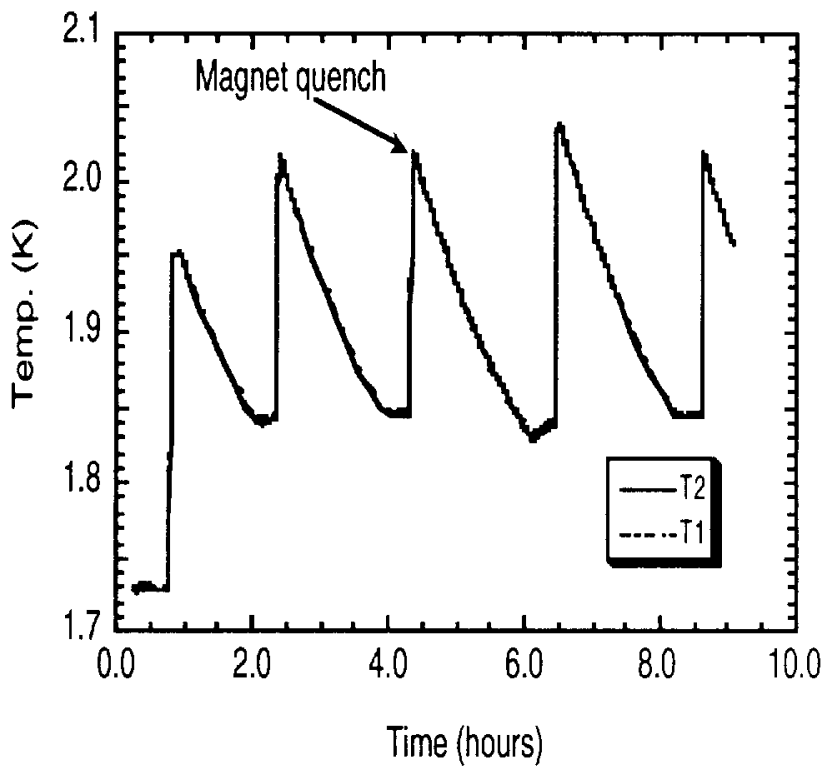

Figure 5 The performance of Cooling cycle after quench.

\section{SUMMARY}

A cryogenics system for a $1.8 \mathrm{~K}$ test facility, for testing high field superconducting magnets at KEK was constructed and tested. A magnet was attached to the vertical double bath cryostat and was cooled down by the refrigeration/liquefier with the automatic computer control system. The cryostat has $8 \mathrm{~W}$ of refrigeration power at $1.9 \mathrm{~K}$ and it took 6 hours to cool down from $4.2 \mathrm{~K}$ to $1.9 \mathrm{~K}$ with $450 \mathrm{~L}$ of liquid helium and 2 tons of the model magnet. The system could be recovered within 2 hours after a quench at $1.9 \mathrm{~K}$. The fast recovery to $1.9 \mathrm{~K}$ after a magnet quench permits several quenches per day and a maximum of five have been demonstrated.

\section{ACKNOWLEDGMENTS}

The authors would like to thank Prof. H. Sugawara, Director General of KEK, Prof. Y. Kimura, Deputy Director of KEK, and Prof. H. Hirabayashi and the former Head of Cryogenics Center for their continuous encouragement during this work. The authors also deeply thank Mechanical Engineering Center and Cryogenics group in Physics Division at KEK.

\section{REFERENCE}

1 Yamamoto, A et al Development of a twin aperture dipole model magnet for the Large Hadron Collider IEEE Trans. Appl. Superc. Vol. 5 (1995) No. 2 1016-1019

2 Yamamoto, A et al Test Results of a Single Aperture 10 Tesla Dipole Model Magnet for the Large Hadron Collider to be published in the Proc. 14th M.T., Tanpere, Finland, 1995

3 Shintomi, T et al Development of a $56 \mathrm{~mm}$ Aperture Superconducting Dipole Magnet for LHC paper presented at Appl. Superc. Conf., Pittsburgh, PA, U.S.A., Aug. 25-30 1996

4 Doi, Y et al Cryogenics system of a 3 Tesla Superconducting Solenoid for the AMY Particle Detector at TRISTAN Adv. Cryo. Eng. Vol. 33 (1988) 551-557

5 Mito, $T$ et al Control System for Helium Refrigerators of TRISTAN Detector Magnets Adv. Cryo. Eng. Vol. 33 (1988) 1105-1112 